\title{
From the Pictorial Symbols of the Theatre to the Virtual Symbolisation of the Real ${ }^{*}$
}

\author{
Theodore Grammatas \\ National and Kapodistrian University of Athens, Athens, Greece
}

\begin{abstract}
In many representative, literary, cinematic, or artistic products of modern civilization, the problem of world's reality and the relationship of the subject with it, are seen from different viewpoints, such as the dimension of the utopian perception of a dreamlike or imaginary composition, subconscious creation, but also more complex versions such as computer mediated complete illusion, artificial intelligence, and control of the brain, intrusion, and influence exerted on the thought of the other using modern technology or any combination of all the above. It is thus understood that the issue at hand can be approached from a variety of viewpoints and aspects, such as the philosophical, psychological, psychoanalytical, technological, neurophysiological, sociological, literary and so on. Our viewpoint is strictly limited to the theatrical dimension and our analysis will progress based on data comprising the theatrical phenomenon, that is, the illusion, as opposed to virtual reality of modern technology.
\end{abstract}

Keywords: theatrical illusion, digital drama, cyber drama, virtual reality

\section{Introduction}

The problem of the existence or not of a reality, which outside the dimension of the intelligent subject, that is, the relationship of the subjectivity of conscience and the objectivity of the world, comprises an issue lending itself to a multiplicity of approaches and dimensions such as ontology, gnosology, psychology, metaphysics, neurophysiology, and sociology (Merleau-Ponty, 2002). The questions posed and the answers given appear in philosophical and literary texts, scholarly studies, and artistic creations, directly or indirectly linked to notions suck as "utopia" and "science fiction", "temporality" and "reality", and "futurity" and "metaphysics". New elements are added to the above as technology develops and there exist newly encountered features, unknown to the "classic" ways of approach, such as robotics and artificial intelligence, cybernetics and virtual reality appear. Based on all these novelties, age old unanswered questions multiply and become broader, very often questioning values and concepts which had once been unquestionable, thus creating a new reality, which is trying more or less successfully every time to answer real or hypothetical questions such as "how can we be sure that we are in a really existing world and not in a cyber-world?", "how do we know we can see the same world as others?", or

\footnotetext{
*Acknowledgements: This research has been co-financed by the European Union (European Social Fund - ESF) and Greek national funds through the Operational Program "Education and Lifelong Learning" of the National Strategic Reference Framework (NSRF) - Research Funding Program: THALIS - UOA-The Theatre as Educational Good and Artistic Expression in Education and Society.

Theodore Grammatas, professor, National and Kapodistrian University of Athens.
} 
finally "is the past just an invention?", since according to Einstein, the distinction between past, present, and future is only a stubbornly persistent illusion. Perhaps then Pedro Calderon de la Barca's view, theatrically expressed in his work Life is a dream (1635) completely responds to Edgar Allan Poe saying that "all we see or seem is but a dream within a dream". Consequently, our thinking broadens up towards the dimension of dream and imagination, utopia, and the subconscious, starting with works such as More's Utopia (1516) and Carrol's Alice in Wonderland (1864), Bronde's Angria (1843) and Machine stops by Foster (1909) and coming as far as current creations, such as The Infernal Desire Machines of Doctor Hoffman by Carter (1972), True Names by Vinge (1981), Cyberpunk by Bethke (1983), Neuromancer by Gibson (1984), and Mind players by Cadigan (1987).

In a more scholarly manner, it is expressed in studies such as Get real: A philosophical adventure in virtual reality by Zhai (1988), Virtual Reality by Rheingold (1991), Virtual Reality and the Exploration of Cyberspace by Hamit (1993), Digital Sensations: Space, Identity and Embodiment in Virtual Reality by Hillis (1999), and Multimedia: From Wagner to Virtual Reality by Packer and Jordan (2001).

Even more than science and literature, it is the cinema and television that are more into examining and making use of "virtual reality". One such early example would be The Practical Joker from the TV series Star Trek: The Animated Series (1974) and later Star Trek: The Next Generation. This was followed by Lisberger's film Tron (1982) and a year later by Trumbull's Brainstorm (1983). Newer and more complicated creations are Until the End of the World by Wenders (1991), Matrix by Wachowski (1999), Avatar by Cameron (2009), and Inception by Nolan (2010). The same concept has been extensively used by "Video Games" as well as in the field of fine arts with installations such as Canadian artist Davies's Virtual Museum (1991).

In these representative scholarly, literary, cinematic, or artistic products of modern civilisation, the problem of world's reality and the relationship of the subject with it, are seen from different viewpoints, such as the dimension of the utopian perception of a dreamlike or imaginary composition, subconscious creation, but also more complex versions such as computer mediated complete illusion, artificial intelligence, and control of the brain, intrusion, and influence exerted on the thought of the other using modern technology or any combination of all the above.

It is thus understood that the issue at hand can be approached from a variety of viewpoints and aspects, such as the philosophical, psychological, psychoanalytical, technological, neurophysiological, sociological, literary and so on. Our viewpoint is strictly limited to the theatrological dimension and our analysis will progress based on data comprising the theatrical phenomenon, that is, the illusion, as opposed to virtual reality of modern technology.

\section{Theatrical Convention/Theatrical Illusion}

The primary and literary meaning of "theatre" is the one referring to a level of deliberate, conscious change brought about to the attitude and behaviour of the individual acting as somebody or something different from what they really are, aiming solely at becoming visible and comprehended by others as seen/shown and not as being in actual reality.

This is the meaning of "mimesis", which is the essence of the theatrical condition, is derived from the transformation of the "natural role", is the real nature of the individual into a "theatrical role", an illusionary 
reality, existence of a certain being (actor), of no material existence, since it is but a "role".

For this to be achieved and for communication between actor as transmitter and viewer as receiver to take place, unuttered acceptance of a convention is required, which precisely marks the notion of "theatre". According to this, both actors on stage and viewers on the stalls are very well aware of the fact that what takes place is not real, but illusionary. Still, they act and exist as if it all were an actual reality. This is the notion of the "theatrical convention" which formulates the role through acting and expresses the "mimesis" as the primary significance of the theatre.

Perfection of the spectacle comprises "as faithful an imitation of an action as possible, so that the viewer keeps forming the false impression that they actually watch the very action" (Diderot, 1962, p. 142). Viewers no longer function as self-existing social beings. Through the creation of an extraordinary (compare: theatrical) place and time, assisted by visual/aural points/elements of the performance as well as their specific position/relationship with the spectacle offered (architecture, viewing aspect), they escape the reality of their own historical time and are transferred to the time dimension shown on stage or they bring the stage time closer to their own as if they were two identical parameters in both quality and essence.This is so, on account of the fact that the viewer, on entering the theatre building, pretends to "believe as real what can be but unreal" (Mannoni, 1969, p. 166).

This release from the objective world is realised via the reduction of the theatre into an illustration of a signifier denoting the real and is subordinate to the signified accepting the view that the theatre comprises a system of signifiers free of any external reality, which function independently and "autonomously" (Pavis, 1976, p. 124). Consequently, the stage, as the place where the particular spectacle is being shown, seems exactly the same as the really existing, in a way which is not just a faithful illustration of reality (of the same essence), but it can sometimes replace reality, appearing in front of the audience as a "slice of life" (Zola, 1881). This "photographic" and not "illustrative" depiction of reality, which ends up being identical to the objectivity being staged in the form of a spectacle, is the most extreme form of imitation of the real which goes beyond the illusion itself, thus turning the performance into a "representation".

The viewer receives a combination of elements from reality, amongst which they place themselves, becoming aware of the self as participating in what is taking place around them (with the presence of the audience in the theatre building), in front of their eyes (stage spectacle) and behind them ("backstage") (Ubersfeld, 1982, p. 43). This palindromic motion among the real and the imaginary, the existing and the illusionary and the conscious adherence to the rules of the game, accepted by the subject from the very moment when individual conscience becomes a collective non-personal being (the viewer), is the unique character and attraction of the theatre.

\section{Virtual Reality}

By "virtual reality", we mean a condition resulting solely from the interaction of a human being as an acting agent with elements of modern technology, taking place in an artificial environment (cyber world), where the physical presence of the individual is substituted for an iconic formulation (Reid, 1995). Subsequently, the actual user of the means communicates with products of their own conscience, while these products appear to objectively exist, although, in essence, they are but iconic projections of the "self" in a virtual world in the circumstances of which the self is participating (Zahoric \& Jenison, 1998, pp. 78-89). The degree of the user's 
interactive involvement depends on the perfection of the technological equipment being used, reaching (at advanced levels) a feeling of total experiential participation in the world of virtual reality (Hillis, 1999).

Virtual reality, depending on its objectives (military, medical, scientific, entertaining) may sometimes identify completely with the real world and other times differ greatly from it, thus creating dreamlike, imaginary surroundings, combined at all times with the given technological "capacities" (Waterworth, 1997, pp. 97-118). This particular communication can take place in a number of ways, either by remote control of a certain device, "joystick", or with the computer "mouse", or other more complicated means, such as wired or wireless glove, eyeglasses or helmet, thus exploiting visual, aural, magnetic, or other stimuli (Slater, Usoh, \& Steed, 1994).

The term first appeared in Oxford English Dictionary as "Virtual Reality" in 1987 at the same named entry, although it had previously existed as "artificial reality", as first mentioned by Krueger in 1970. In an embryonic form the term first appeared in 1938, when Artaud in his study The Theatre and Its Idol talked about a "spectacular power of a visionary alchemy of inner drama".

We can include a number of simultaneously expressed notions, such as the ones referring to some of its particular aspects, for example the influence it can exert on human mind and behaviour, and the transfer of illusions into people's real lives. At the time during which the subject/user of the specific technology, participates experientially in the virtual world projected in front of them, they lose any freedom of thought and expression and are turned into an acting conscience in a robotic way, since they do not act in a self-derived conscious manner, but in a way directed by external factors setting their reflexes into motion via mechanisms affecting the brain, both the conscious and the subconscious. In this manner, virtual symbolisation of the real totally replaces the mimetic reproduction or reality and simulation.

This condition can be explained in a number of ways with a psychological and mental content, easily verified in various frames of reference. For instance, it can be suggested that when the conscience of the thinking subject is loosely energised, that is, when attention is distracted and external stimuli come from a number of different sources, there is an impression of longer time duration or that time passes really slowly (Welch, 1999). In contrast, the more focused the subject's attention is, the greater the concentration, the more intense the reflection, the less the awareness of the surroundings and the shorter the experience of the passing time. The thinking subject remains almost completely unaware of the true limits of their own body and the surrounding space. Consequently, conscience is mentally absent, thus giving rise to a condition of an "absent presence" (Waterworth \& Waterworth, 2001, pp. 205-208)

A first stage of this condition, still in the state of illusion, is the case of the naturalistic theatre and its version as a "slice of life". Simulation of reality on stage, although secondary, it may still cause a feeling of total identification of the viewer with the spectacle, thus functioning as "illustration" rather than "symbolisation" of the real. A similar notion can be observed in the genre of "folk theatre" or "theatre for children" (Grammatas, 1996), where the absence of theatrical illusion causes a different condition for communication between the stage and the stalls, which, in a way, turns the stage into an extension of the stalls. The consequences of the absence of a conscious convention can be seen in the cinema, in its first appearance, when members of the audience sitting in the front rows had to be relocated so that a railway shown on screen as entering the station "Gare de Lyon" in Paris, would be allowed to go past in the Lumière brothers' film, also approaching the viewers themselves, as well as in contemporary films using complex technologies. 
Another case where the basic content of the conscience as present absence is evident is that of the magician's trick, which is mainly due to the disorientation of the viewer and carrying their focus of attention to a space different from the one where the trick is actually taking place.

\section{Theatrical Illusion-Virtual Reality}

As understood, theatrical reality, made up of a "convention" and "illusion" in the viewer's conscience, and also an "imitation" and a "role" on the part of the actor, has a lot in common with the "simulation" of virtual reality, which allows for a comparative approach and a reciprocal correlation (Baudrillard, 1981, pp. 16-17).

Their basic element is the secondary signification of reality, which, in the form of imitation or simulation, reproduces, formulates, and illustrates an environment at various degrees of fidelity, within which environment and for certain duration of time, the subject is placed and functions. This illustrative projection, performance, or representation of reality as a phaenomenon of no essence involves the conscience in a direct experiential manner allowing for the development of reciprocal interactive communication between this very projection as subject and the projected image as object, resulting in a situation which, although not existing in the objective dimension, is perceived and actually functions as such (Abercombie \& Longhurst, 1988). Hence the similarity of the two concepts offered for analysis, which legalises a comparative approach, at the same time allowing their individuality and their essential differences to become apparent.

The way illusion functions is common in both cases, with a few but essential partial differences, which lead to distinguishing two different forms and categories of illusion, corresponding to these two different forms of social and cultural structure. The first, the theatrical, corresponds to the society and culture of the spectacle, where the world is illustrated and is perceived as "res extensa" in an illusionary manner, through the theatrical convention. The second, virtual reality, corresponds to the parameters of the internet and multimedia culture, where the world is part of a "res cogitans" projected in cyberspace.

The distinction between the two is one that can be made between the extrinsic perception of the world on the one hand and its intrinsic perception on the other, which correspond to the physical reality of the theatre and the virtual reality of simulation. While theatrical communication, and theatrical illusion, lasts, the viewer's conscience exercises a certain degree of freedom in perceiving the stage act, at the same time being able to perceive the presence of the self as acting power involved in the space and time of the performance. This way the subjective/conscious space and time coincides with the stage/dramatic time and the latter in its turn with the objective/countable space and time. Under these circumstances it is understood that the viewer in the theatre building comprises an "absent presence" constantly and consciously lying, recording the presence of the stage world, now perceived as real, within the void created by this very absence.

In order for the world of stage act to be created, it is necessary for the actor to play the subject with ought being the viewer of it. These persons, the actors, function not as physical entities, but as theatrical roles, which means that they in their own turn also become part in the dimension of an "illusionary perception", which they embrace and realise at the same degree as the viewer does, based upon the reciprocal "convention" governing the particular form of communication. In contrast, in the case of simulated reality, the conscience of the individual functions as "present absence" since, though physically existing in the world of objectivity, it is essentially absent from it, completely identifying with the hologram of the pictorially projected world (Bystrom, 
Barfield, \& Hendrix, 1999).

The thus presented illustration of the real, within which the subject/user finds themselves, is the result of their own conscience, despite the fact that it is undoubtedly existing, in fact being but a symbolised depiction, extrinsically expressing the conscience's own parameters, in the void of a non-existing reality, formulated through technology ( Waterworth \& Waterworth, 2001). The illusion caused, though seemingly sharing the same features as those of the theatre, is still quite different, as the following analysis will show, since simulation and cyberspace do not identify neither with the secondary theatrical signification nor with the imitation or the role.

In an attempt to record the differences between the two types of communication, that of the theatre and that of simulation, it can be noted that they are traced along three axes, present in both categories: the ontological, that is the dimension of place and time where the individual exists, where the real world of the theatre is in complete contrast to that of virtual reality; the existential, that is the level on which the subject's presence is formulated, where the "absent presence" of theatrical reality is distinguished from the "present absence" of virtual reality; finally, the conscientious, that is, the way and quality in which conscience functions. In this the dimension and fragmentation characterising the viewer's communication with the spectacle is distinctly different from the total focus of attention and the concentrated action of the user of modern technology. With such prerequisites and such a frame of reference, examination of the issue in question can proceed to look into the process of mediation and the conditions of communication between the subject/transmitter and the object/ receiver.

The first difference can be observed in the relationship between the intra-conscious and the extra-conscious levels in both cases. In the theatre, the contact of the viewer with the spectacle and the corresponding development of illusion take place at the same time, within and outside the subject's conscience, causing a relationship which is at the same time cerebral and emotional, autonomous and dependent on the perceived stimulus, the theatrical performance. On the contrary, communication via technological means and development of virtual reality, takes place solely intra-conscientiously, in a cerebral manner, in a completely dependent relationship, which binds the subject to the product of symbolised reality. This results in the relationship being absolutely committing, in contrast to that of the theatre, in which communication takes place freely, since the viewer can choose what they want to see from the projected stage act, which can vary from the aspect of another viewer watching the same act at the same time and place. Consequently, space and time, though determining any communicative relationship, do not cause it to become one unique way of perception, as it is being influenced by a number of other factors, subjective and objective, intentional of coincidental, which makes each experience unique in its own right.

In the case of cyberspace, this is not true, as the illusion of the presence and participation of the user in the projected hologram, though a lot more convincing and true-like than that of the theatre, is realised solely via the vehicle of modern technology.

In the theatre, illusion is a conscious product and a necessary prerequisite for the function of the very concept. What is being criticised and looked down upon in real life, "the lie", in the world of the theatre comprises the uttermost value, since it is from that the concept of communication and perception of the stage act is derived. Still, the consciously lying viewer can enter and exit the illusionary world of the theatre at will, at the same time having the ability of a double function: that of experiential immersion in the spectacle as well as that of their own personal lives, given the fact that their thought is capable of judging the pictorial symbols of the 
performance, and their real position at the stalls amongst the other members of the audience.

Conversely, in the case of virtual reality, independence and free will cease to exist. An intrinsic monitoring system is imposed via the technological means causing the conscience to completely depend on the very means (Zahoric \& Jenison, 1988, pp. 78-89). The supposed product of the subject's mental and psychological functions is externally imposed, and the subject being unaware of this takes it as a real, completely personal choice and creation. This way the conscience is trapped in the dimension of virtual reality and the simulation of the real, part of which the subject's own existence seems to be, not allowing the subject to doubt the self, thus not allowing any doubt about the world perceived by the self (Kelso, Weyhrauch, \& Bates, 1993).

Though the "theatrical lie" is conscious, the "virtual lie" is unconscious, ceasing to exist from the moment it is conceived when the technological means ceases to function. The degree of identification, the intensity and the duration of the illusion, and the focus of the subject on the projected pictorial world are all instrumental in achieving this condition. This intensity is rather non-continual and rather relaxed in the theatre, allowing the concurrent function of conscience in two different spaces and two different dimensions, that of the stage and that of the stalls. On the contrary, the totally experiential immersion in the world of virtual reality binds the conscience in a committing manner thus developing a complete illusion (Dreyfus \& Dreyfus, 1986).

\section{Conclusion}

According the above analysis, the illusionary perception of the theatrical performance differs greatly from the pictorial symbolisation of the world generated from the use of modern technology. The absent presence of conscience in the former is world apart from the present absence in the latter. Although two distinct categories in terms of their means and aims, which do not lend themselves to comparative assessment but only a comparative approach, it can be claimed that despite the superiority of technology in producing a true-like pictorial world, the theatrical illusion remains unsurpassed. Imitation continues to trigger the imagination and emotions a lot more than simulation, which definitely binds. The freedom in the viewer's "sight"' is superior to the captured attention resulting from external factors. Finally, the feeling of community and the differentiated response of the individual is far more creative from the determinism of the technically imposed picture.

\section{References}

Abercrombie, N., \& Longhurst, B. (1998). Audience: A sociological theory of performance imagination. London: Sage. Baudrillard, J.(1981). Simulacres et simulations (Simulacra and Simulation). Paris: Galilée.

Bystorm, K. E., Barfield, W., \& Hendrix, C. (1999). A conceptual model of the sens of presence in virtual environement. Presence:Teleoperators and Virtual Environements ,8(2), 241-244.

Diderot, D. (1962). Oeuvres Romanesques (Complete works). Paris: Garnier.

Dreyfus, H.L., \& Dreyfus, S. E. (1986). Mind over machine.The power of human intuition and expertise in the era of the computer. Cambridge: Basil Blackwell Ltd..

Goslin, M, \& Morie, J. F. (1996). "Virtopia” Emotional experiences in virtual environments. Leonardo, 29(2), 95-100.

Grammatas, T. (1996). Fantasyland.Young publics theatre. Athens: Typothito.

Hillis, K. (1999). Digital sensations: Space, identity and embodiment in virtual reality. Minneapolis: University of Minnesota Press. Kelso, M., Weyhrauch, T. P., \& Bates, J. (1993). Dramatic presence. Presence: Teleoperators and Virtual Enviornments, 2(1), $1-15$.

Mannoni, O. (1969). Clefs pour l'imaginaire (Keys to the imaginary scene). Paris: Seuil.

Melreau-Ponty, M. (2002). Phenomenology of perception. London: Routledge.

Pavis, P. (1976). Problèmes de sémiologie théâtrale (Theatrical semiology problems). Montréal: Presses de l'Université du Québec. 
Reid, E. (1995). Cybersociety, Thousand Oaks. CA: Sage.

Slater, M., Usoh, M., \& Steed, A. (1994). Depth of presence in virtual environements. Presence: Teleoperators and Virtual Environements, 3(2), 130-144.

Sondel, B. (1939). Zola's naturalistic theory with particular references to the drama. Chicago: University of Chicago Libraries.

Ubersfeld, A. (1982). Lire le thèatre (Reading theatre) ( $4^{\mathrm{e}}$ éd.). Paris: Editions Sociales.

Waterworth, E., \& Waterworth, J. (2001). Focus, locus and sensus: The three dimensions of virtual experience. CyberPsychology \& Behavior, 2, 203-213.

Waterworth, J. A. (1997). Personal spaces: 3D spatial worlds for information exploration, organization and communication. In R. Earnshaw, \& J. Vince (Eds.) The internet in 3D: Information, images, and interaction (97-118). London: Academic Press.

Welch, R. B. (1999). How can we determine if the sense of presence affects task performance? Presence: Teleoperators and Virtual Environements, 8(5), 574-577.

Zahoric, P., \& Jenison, R. L. (1998). Presence as being-in-the-world. Presence: Teleoperators and Virtual Environments, 7(1), 78-89.

Zola, E. (1881). Le naturalisme au théâtre-Les théories et les exemples (Naturalisme on Theatre.Theories and examples). Paris: G. Charpentier. 